\title{
Synergistic Effect of [10]-Gingerol and Aminoglycosides against Vancomycin-Resistant Enterococci (VRE)
}

\author{
Chihiro Nagoshi, ${ }^{a}$ Sumiko Shiota,,${ }^{b}$ Teruo Kuroda, ${ }^{a}$ Tsutomu Hatano, ${ }^{c}$ Takashi YoshidA, ${ }^{c}$ \\ Reiko KariYAMA, ${ }^{d}$ and Tomofusa TsuchiYA ${ }^{*, a}$ \\ ${ }^{a}$ Department of Molecular Microbiology, Graduate School of Medicine, Dentistry and Pharmaceutical Sciences, Okayama \\ University; ' Department of Pharmacognosy, Graduate School of Medicine, Dentistry and Pharmaceutical Sciences, \\ Okayama University; Tsushima, Okayama 700-8530, Japan: ${ }^{d}$ Department of Urology, Graduate School of Medicine, \\ Dentistry and Pharmaceutical Sciences, Okayama University; Shikata, Okayama 700-8558, Japan: and ${ }^{b}$ Laboratory of \\ Pathogenic Microbiology, School of Pharmacy, Shujitsu University; Nishigawara, Okayama 703-8516, Japan.
}

Received July 8, 2005; accepted November 30, 2005; published online December 5, 2005

\begin{abstract}
An extract from ginger (root of Zingiber officinale) reduced the minimum inhibitory concentrations (MICs) of aminoglycosides in vancomycin-resistant enterococci (VRE). The effective compound was isolated and identified as [10]-gingerol. In the presence of [10]-gingerol at 1/10 concentration of its own MIC, the MIC of arbekacin was lowered by $1 / 32$ to $1 / 16$. [10]-Gingerol also reduced the MICs of other aminoglycosides, and of bacitracin and polymixin B, but not of other antimicrobial agents tested. Because [10]-gingerol reduced the MICs of several aminoglycosides both in strains possessing or lacking aminoglycoside-modification enzymes, it seems that the effect of [10]-gingerol is not related to these enzymes, which mainly confer bacterial resistance against aminoglycosides. It seemed that a detergent-like effect of [10]-gingerol potentiated the antimicrobial activity of the aminoglycosides. In fact, some detergents such as sodium dodecyl sulfate (SDS) and Triton X-100 reduced the MICs of aminoglycosides, bacitracin and polymixin B in VRE. Since the intrinsic resistance to aminoglycosides in enterococci is due to low level of entry of the drugs into the cells, increase in the membrane permeability caused by [10]-gingerol will enhance the influx of aminoglycosides into enterococcal cells.
\end{abstract}

Key words [10]-gingerol; arbekacin; vancomycin-resistant enterococci (VRE); aminoglycoside

Enterococci have not been regarded as serious pathogenic bacteria, but these days it is known that they cause nosocomial infections like urinary tract infection and postoperative septicemia. Vancomycin, or the combination of aminoglycosides and $\beta$-lactams, has been an effective therapy for infections caused by the enterococci. ${ }^{1)}$

The intrinsic low-level resistance of enterococci to the aminoglycosides is due to the inefficient entry into cells across the cytoplasmic membrane. ${ }^{2)}$ Aminoglycosides are usually combined with $\beta$-lactam antibiotics, the inhibitors of cell wall synthesis, which may facilitate entry of aminoglycosides, ${ }^{3)}$ and the combination of ampicillin and gentamicin is one of the reliable therapies for the treatment of enterococcal infection. ${ }^{1)}$ However cases of infections with multidrug resistant enterococci including high-level gentamicin and ampicillin resistant enterococci are increasing and becoming a major problem. ${ }^{4)}$ Many of the high-level ampicillin resistant strains of Enterococus faecium are also resistant to vancomycin. ${ }^{5)}$ In such strains, the combination therapies are no longer effective. ${ }^{6}$

Thus, it is necessary to find new therapies that are effective for the treatment of infections caused by such multidrug resistant enterococci. If we can inhibit mechanisms that confer drug resistance to bacteria, activity of antimicrobial agents against the resistant bacteria could be restored. The combination of such an inhibitor and an antimicrobial agent should be effective for infectious diseases caused by drug-resistant bacteria, similar to the combination therapy of $\beta$-lactam and $\beta$-lactamase inhibitor.

Several compounds have been reported as inhibitors of the aminoglycoside-modification enzymes that are mainly involved in acquired aminoglycoside resistance in enterococci. Wortmannin has reported the inhibition of $\mathrm{AAC}\left(6^{\prime}\right)$
$\operatorname{APH}\left(2^{\prime \prime}\right)$ (aminoglycoside acetyltransferase(6')-aminoglycoside phosphoryltransferase $\left.\left(2^{\prime \prime}\right)\right){ }^{7)}$ Another study suggested that quercetin, known as a protease inhibitor, inhibited one of the aminoglycoside-modification enzymes, APH( $\left.3^{\prime}\right)$-IIIa (aminoglycoside phosphoryltransferase( $\left.3^{\prime}\right)$-IIIa), and the isoquinolinesulfonamides inhibited the function of both $\mathrm{APH}\left(3^{\prime}\right)$-IIIa and AAC $\left(6^{\prime}\right)-\mathrm{APH}\left(2^{\prime \prime}\right)$. However, they did not potentiate the antimicrobial activity of the aminoglycosides in the strain that possessed these enzymes. ${ }^{8)}$

Arbekacin is one of the aminoglycosides used for the treatment of infections caused by gentamicin- and methicillin-resistant Staphylococcus aureus (MRSA) in Japan. It is stable against many aminoglycoside-modification enzymes. Although it is inactivated by $\mathrm{AAC}\left(6^{\prime}\right)-\mathrm{APH}\left(2^{\prime \prime}\right)$, it is modified at a lower rate by the enzyme than is gentamicin. ${ }^{9)}$ Several studies have shown synergistic activity of the combination of ampicillin and arbekacin against high-level gentamicin-resistant enterococci in vitro or in vivo. ${ }^{9-11)}$ The authors suggested the possibility of a combination therapy comprised of ampicillin and arbekacin for treatment of infections caused by gentamicin-resistant VRE.

Here we report that [10]-gingerol isolated from ginger reduced the MIC of aminoglycosides in VRE. The combination of [10]-gingerol and arbekacin acted synergistically against enterococci including VRE regardless of the presence or absence of the modification enzyme $\mathrm{AAC}\left(6^{\prime}\right)-\mathrm{APH}\left(2^{\prime \prime}\right)$.

\section{MATERIALS AND METHODS}

Bacteria and Growth E. faecalis ATCC51299 and E. faecium 11506 are vancomycin resistant enterococci (VRE) that possess vanB or vanA, respectively, as vancomycin resistant determinants. These strains have $\operatorname{aac}\left(6^{\prime}\right)-\operatorname{aph}\left(2^{\prime \prime}\right)$ as 
aminoglycosides resistant determinants. E. faecium 11506 is a multidrug resistant strain, and is resistant to many drugs such as ampicillin, erythromycin and norfloxacin. E. faecalis ATCC29212 and E. faecium OU94 do not possess vanA, van $B$ or $\operatorname{aac}\left(6^{\prime}\right)-\operatorname{aph}\left(2^{\prime \prime}\right)$. E. faecium 11506 and E. faecium OU94 are clinical isolates.

Determination of Antimicrobial Susceptibilities The minimum inhibitory concentrations (MICs) were determined in cation-supplemented Mueller-Hinton broth (CSMHB), Mueller-Hinton broth (Difco Laboratories) supplemented with $\mathrm{CaCl}_{2}(50 \mu \mathrm{g} / \mathrm{ml})$ and $\mathrm{MgSO}_{4}(25 \mu \mathrm{g} / \mathrm{ml})$, by a microdilution method. ${ }^{12)}$ Growth of the cells was scored after $24 \mathrm{~h}$ of incubation at $35^{\circ} \mathrm{C}$. Extract from the plant was first dissolved in dimethylsulfoxide (DMSO) and then diluted into MHB. DMSO at 1 or $2 \%$ concentration caused no inhibition of bacterial growth. The fractional inhibitory concentration (FIC) index was calculated as reported. ${ }^{13)}$ The effects of the drugs were interpreted to be indicative of synergy or indifference when the index was lower than or equal to 0.5 or larger than 0.5 , respectively.

Isolation of Effective Compounds from Ginger Five hundred grams of ginger was extracted with 11 of $n$-hexane and $10 \mathrm{~g}$ of $n$-hexane extract was obtained. Eight grams of the $n$-hexane extract from ginger was subjected to column chromatography over DIAION HP20 (Mitsubishi Kasei Co. Ltd.) and eluted with $\mathrm{H}_{2} \mathrm{O}$ and aqueous methanol in a stepwise manner. Active fractions (100\% methanol fraction, $1.0 \mathrm{~g}$ ) were collected and purified by preparative high-performance liquid chromatography on YMC pack ODS-AQ324 (1 by $30 \mathrm{~cm}$ ) by using $60 \%$ acetonitrile as an eluant. We repeated this step one more time, and obtained $110 \mathrm{mg}$ of a purified compound. The structure of this isolated compound dissolved in acetone- $d_{6}$ with $\mathrm{D}_{2} \mathrm{O}$ was determined by ${ }^{1} \mathrm{H}-$ NMR spectral analysis.

Viable Cell Number Time-kill experiments were performed to examine the effects of the combination of drug and [10]-gingerol. An overnight culture was diluted 1000fold with fresh Brain Heart Infusion (BHI) broth (Difco Co.) containing either arbekacin or [10]-gingerol, or both, as indicated in the figure legend. Samples were taken after 1, 2, 3, 6,9 and $24 \mathrm{~h}$ of incubation at $37^{\circ} \mathrm{C}$, and serial dilutions were made in saline before samples were plated onto a nutrient agar. Colony forming units (CFU) were determined. The rate and extent of killing were determined by plotting viable colony counts $\left(\log _{10} \mathrm{CFU} / \mathrm{ml}\right)$ versus time.

Materials Ginger was from Eidai-yakugyou Co., Ltd. This ginger conforms to the Japanese pharmacopeia. Arbekacin was obtained from Meiji Seika Co. (Tokyo, Japan), and other antimicrobial agents used in this study were from commercial sources.

\section{RESULTS}

Isolation and Identification of the Effective Compound We found that ginger extract reduced the MICs of aminoglycosides in enterococci strains, but it did not affect the MICs of other types of antimicrobial agents such as ampicillin (data not shown). Using successive column chromatography, we isolated the effective compound and identified it to be [10]-gingerol (Fig. 1). The MICs of ginger extract and [10] gingerol against all enterococcal strains used in this study

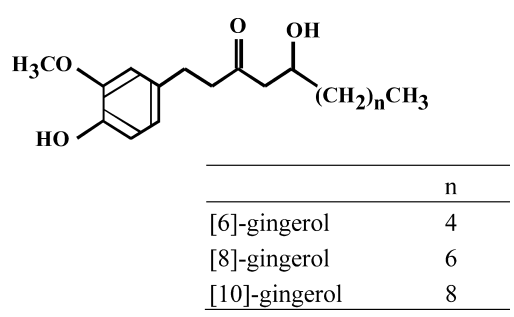

Fig. 1. Structure of [10]-Gingerol and Its Structural Analogs

Table 1. Effect of Ginger Extract and [10]-Gingerol on Antimicrobial Activity of Arbekacin in Enterococci

\begin{tabular}{lrcc}
\hline \hline & \multicolumn{3}{c}{ MIC of arbekacin $(\mu \mathrm{g} / \mathrm{ml})$} \\
\cline { 2 - 4 } Bacteria & - & $\begin{array}{c}\text { +Ginger extract } \\
(20 \mu \mathrm{g} / \mathrm{ml})^{a)}\end{array}$ & $\begin{array}{c}+[10]-G i n g e r o l \\
\left.(20 \mu \mathrm{g} / \mathrm{ml})^{a}\right)\end{array}$ \\
\hline E. faecalis & 128 & 1 & $4(0.13)^{b)}$ \\
ATCC51299 & 64 & 1 & $4(0.056)$ \\
ATCC29212 & & & $2(0.17)$ \\
E. faecium & 32 & 1 & $2(0.23)$ \\
11506 & 16 & 1 & \\
OU94 & & &
\end{tabular}

a) The concentrations added to the medium are lower than $1 / 10$ of their MICs. b) FIC index is shown in the parenthesis.

were higher than or equal to $4000 \mu \mathrm{g} / \mathrm{ml}$ and 200 $400 \mu \mathrm{g} / \mathrm{ml}$, respectively. Thus, their antibacterial activities were very low. However the MIC of arbekacin was remarkably reduced in the presence of ginger extract $(200 \mu \mathrm{g} / \mathrm{ml})$ or [10]-gingerol $(20 \mu \mathrm{g} / \mathrm{ml})$ (Table 1$)$. The concentrations used were lower than $1 / 10$ of the MICs. The FIC index was calculated for the enhanced antibacterial effect of arbekacin and [10]-gingerol. The FIC index for arbekacin in combination with [10]-gingerol ranged from 0.056 to 0.23 in the enterococcal strains. These results indicate that the antibacterial effect of arbekacin plus [10]-gingerol is synergistic. Among four strains used in these experiments, two of them possessed $\operatorname{aac}\left(6^{\prime}\right)-\operatorname{aph}\left(2^{\prime \prime}\right)$ that confers arbekacin resistance against enterococci and other two strains that did not possess aac $\left(6^{\prime}\right)$ $\operatorname{aph}\left(2^{\prime \prime}\right)$. The synergistic effect was observed in all strains. It seems that this synergistic effect is not related to the aminoglycosides-modification enzyme.

Effect of Arbekacin and [10]-Gingerol on Cell Viability Arbekacin has a bactericidal effect. We compared the effect of arbekacin and [10]-gingerol on cell viability with two types of E. faecalis: with and without $\operatorname{aac}\left(6^{\prime}\right)-\operatorname{aph}\left(2^{\prime \prime}\right)$ (Fig. $2)$. Viable cell numbers were little affected in the presence of arbekacin $(8 \mu \mathrm{g} / \mathrm{ml})$ or of [10]-gingerol $(20 \mu \mathrm{g} / \mathrm{ml})$ alone. On the other hand, simultaneous addition of arbekacin and [10]gingerol dramatically reduced the viable cell numbers. The synergistic bactericidal effect was observed both in the two types of $E$. faecalis with or without $\operatorname{aac}\left(6^{\prime}\right)-\operatorname{aph}\left(2^{\prime \prime}\right)$.

Effect of [10]-Gingerol on MICs of Various Aminoglycosides Aminoglycoside antibiotics are inactivated by several kinds of aminoglycoside-modification enzymes such as AAC, APH, and aminoglycoside adenylyltransferase (AAD) (Table 2). Arbekacin and gentamicin are inactivated by the bi-functional enzyme $\mathrm{AAC}\left(6^{\prime}\right)-\mathrm{APH}\left(2^{\prime \prime}\right)$; tobramycin is inactivated by $\mathrm{AAC}\left(6^{\prime}\right)-\mathrm{APH}\left(2^{\prime \prime}\right)$ and $\mathrm{APH}\left(2^{\prime \prime}\right)$; kanamycin is inactivated by $\mathrm{AAC}\left(6^{\prime}\right)-\mathrm{APH}\left(2^{\prime \prime}\right), \operatorname{APH}\left(2^{\prime \prime}\right)$ and $\mathrm{APH}\left(3^{\prime \prime}\right)$. On the other hand, streptomycin is inactivated only by $\mathrm{APH}\left(3^{\prime \prime \prime}\right)$ 
among the enzymes listed in Table 2. We investigated the effect of [10]-gingerol on the MICs of these aminoglycosides in the E. faecalis and E. faecium strains. [10]-Gingerol reduced the MICs of arbekacin, gentamicin and tobramycin. The MIC of streptomycin that is not affected by AAC $\left(6^{\prime}\right)$ $\operatorname{APH}\left(2^{\prime \prime}\right)$ was also reduced by [10]-gingerol. Since the reduction of the MIC occurred regardless of the existence of these aminoglycoside-modification enzymes, the mechanism by which [10]-gingerol potentiated the antimicrobial activity of aminoglycoside is not related to the inhibition of the aminoglycoside-modification enzymes.

Effect of [10]-Gingerol on the MICs of Other Antimicrobial Agents In the presence of $20 \mu \mathrm{g} / \mathrm{ml}$ of [10]-gingerol, the MICs of both bacitracin and polymixin B were reduced in both E. faecalis and E. faecium. The reduction in the MIC of fosfomycin was seen only in E. faecalis strains (Table 3). Bacitracin and fosfomycin are inhibitors of cell wall synthesis, and polymixin B causes damage in the cell membrane. Because these three drugs cause damage to the cell wall or the cell membrane, and because [10]-gingerol is a hydrophobic compound, it seemed that [10]-gingerol has a similar effect on the membrane, and that the combination of [10]-gingerol with each of these three drugs gives synergistic (a)

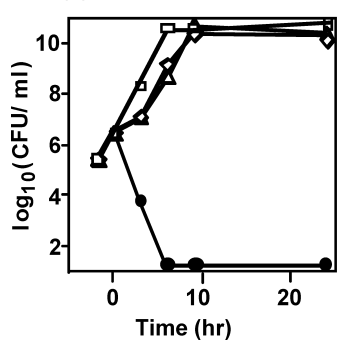

(b)

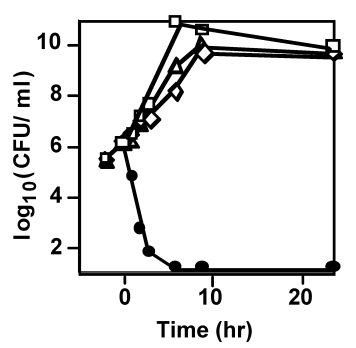

Fig. 2. Effect of [10]-Gingerol and Arbekacin on Viable Cell Numbers of E. faecalis

Cells of E. faecalis (a) ATCC51299 possessing $\mathrm{AAC}\left(6^{\prime}\right)-\mathrm{APH}\left(2^{\prime \prime}\right)$ and (b) ATCC29212 not possessing AAC $\left(6^{\prime}\right)-\mathrm{APH}\left(2^{\prime \prime}\right)$ grown in BHI broth were diluted with fresh medium and incubated at $37^{\circ} \mathrm{C}$ under aerobic conditions in the absence (open square), or presence of arbekacin $(8 \mu \mathrm{g} / \mathrm{ml})$ (open diamond), [10]-gingerol $(20 \mu \mathrm{g} / \mathrm{ml})$ (open triangle), or arbekacin $(8 \mu \mathrm{g} / \mathrm{ml})$ plus [10]-gingerol $(20 \mu \mathrm{g} / \mathrm{ml})$ (closed circle) Samples were taken at the indicated time points, and viable cell numbers were counted as described under Materials and Methods. antimicrobial effects on enterococcal cells.

Effect of Length of Alkyl Group of Gingerol on the Synergistic Activity with Arbekacin Among the three gingerols, [6]-gingerol, [8]-gingerol and [10]-gingerol, [10]gingerol was found to be the most effective compound regarding the reduction of the MIC of arbekacin (Table 4). The structures of these compounds are shown in Fig. 1. It seems that the length of the alkyl group is related to the activity, and the degree of potentiation depends in part on the hydrophobic portion of the molecules.

Table 3. Effect of [10]-Gingerol on the MICs of Other Antimicrobial Agents

\begin{tabular}{|c|c|c|c|c|c|}
\hline \multirow{4}{*}{ Agents $^{a)}$} & \multirow{4}{*}{$\begin{array}{c}{[10]-} \\
\text { Gingerol }^{b)}\end{array}$} & \multicolumn{4}{|c|}{ MIC against strain $(\mu \mathrm{g} / \mathrm{ml})$} \\
\hline & & \multicolumn{2}{|c|}{ E. faecalis } & \multicolumn{2}{|c|}{ E. faecium } \\
\hline & & ATCC & ATCC & 11506 & OU94 \\
\hline & & 51299 & 29212 & 11000 & דנט \\
\hline \multirow[t]{2}{*}{$\mathrm{ABPC}$} & - & 1 & 1 & 256 & 1 \\
\hline & + & 1 & 1 & 128 & 1 \\
\hline \multirow[t]{2}{*}{ FM } & - & 128 & 64 & 64 & 32 \\
\hline & + & 32 & 16 & 64 & 32 \\
\hline \multirow[t]{2}{*}{$\mathrm{VCM}$} & - & 64 & 2 & 1024 & $<1$ \\
\hline & + & 64 & 2 & 512 & $<1$ \\
\hline \multirow[t]{2}{*}{ EM } & - & $>1024$ & 1 & $>1024$ & 1 \\
\hline & + & $>1024$ & 1 & $>1024$ & 1 \\
\hline \multirow[t]{2}{*}{$\mathrm{TC}$} & - & 0.125 & 2 & 8 & 0.125 \\
\hline & + & 0.125 & 1 & 4 & 0.125 \\
\hline \multirow[t]{2}{*}{ NFLX } & - & 2 & 4 & 64 & 8 \\
\hline & + & 2 & 4 & 64 & 8 \\
\hline \multirow[t]{2}{*}{ BK } & - & 4 & 4 & 4 & 4 \\
\hline & + & 2 & 2 & 2 & $\mathrm{ND}^{c)}$ \\
\hline \multirow[t]{2}{*}{$\mathrm{CH}$} & - & 8 & 4 & 8 & 8 \\
\hline & + & 2 & 2 & 2 & 2 \\
\hline \multirow[t]{2}{*}{$\mathrm{BC}$} & - & 64 & 64 & 256 & 128 \\
\hline & + & 16 & 16 & 32 & 32 \\
\hline \multirow[t]{2}{*}{ PL-B } & - & $>1024$ & $>1024$ & 1024 & 512 \\
\hline & + & 128 & 64 & 32 & 32 \\
\hline
\end{tabular}

a) ABPC, ampicillin; FM, fosfomycin; VCM, vancomycin; EM, erythromycin; TC tetracycline; NFLX, norfloxacin; BK, benzalkonium chloride; $\mathrm{CH}$, chlorhexidine gluconate; $\mathrm{BC}$, bacitracin; PL-B, polymyxin B. b) The concentration of [10]-gingerol added to the medium is $20 \mu \mathrm{g} / \mathrm{ml}$ and is lower than $1 / 10$ of its own MIC against enterococcal cells. c) ND, not determined.

Table 2. Effect of [10]-Gingerol on MICs of Various Aminoglycosides in Enterococci in the Presence or Absence of Aminoglycoside-Modification Enzymes

\begin{tabular}{|c|c|c|c|c|c|c|c|c|c|}
\hline \multirow{4}{*}{ Agents $^{a}$ ) } & \multirow{4}{*}[10]{-Gingerol $^{b)}$} & \multicolumn{4}{|c|}{$\operatorname{MIC}(\mu \mathrm{g} / \mathrm{ml})$} & \multirow{2}{*}{\multicolumn{4}{|c|}{ Aminoglycoside-modification enzyme }} \\
\hline & & \multirow{2}{*}{\multicolumn{2}{|c|}{ E. faecalis }} & \multirow{2}{*}{\multicolumn{2}{|c|}{ E. faecium }} & & & & \\
\hline & & & & & & \multirow{2}{*}{$\begin{array}{l}\operatorname{AAC}\left(6^{\prime}\right)- \\
\operatorname{APH}\left(2^{\prime \prime}\right)\end{array}$} & \multirow{2}{*}{$\operatorname{APH}\left(2^{\prime \prime}\right)$} & \multirow{2}{*}{$\mathrm{APH}\left(3^{\prime}\right)$} & \multirow{2}{*}{$\mathrm{APH}\left(3^{\prime \prime}\right)$} \\
\hline & & $\begin{array}{l}\text { ATCC } \\
51299\end{array}$ & $\begin{array}{l}\text { ATCC } \\
29212\end{array}$ & 11506 & OU94 & & & & \\
\hline \multirow[t]{2}{*}{$\mathrm{ABK}$} & - & 128 & 64 & 32 & 16 & Inact. $^{c)}$ & - & - & - \\
\hline & + & 4 & 4 & 2 & 2 & $(50 \%)$ & & & \\
\hline \multirow[t]{2}{*}{ GM } & - & 256 & 16 & $>4096$ & 16 & Inact. & - & - & - \\
\hline & + & 8 & 4 & 1024 & 4 & & & & \\
\hline \multirow[t]{2}{*}{ TOB } & - & 64 & 16 & 4096 & 512 & Inact. & Inact. & - & - \\
\hline & + & 8 & 4 & 512 & 32 & & & & \\
\hline \multirow[t]{2}{*}{$\mathrm{KM}$} & - & $>4096$ & 64 & $>4096$ & 1024 & Inact. & Inact. & Inact. & - \\
\hline & + & $>4096$ & 8 & $>4096$ & 128 & & & & \\
\hline \multirow[t]{2}{*}{ SM } & - & $>8192$ & 256 & 8192 & 64 & - & - & - & Inact. \\
\hline & + & 2048 & 32 & 2048 & 32 & & & & \\
\hline
\end{tabular}

a) $\mathrm{ABK}$, arbekacin; GM, gentamicin; TOB, tobramycin; KM, kanamycin; SM, streptomycin. $\quad b$ ) The concentration of [10]-gingerol added to the medium is $20 \mu \mathrm{g} / \mathrm{ml}$ and is lower than 1/10 of its own MIC against enterococcal cells. c) "Inact." means that the aminoglycoside-modification enzyme can modify the aminoglycoside and can inactivate it. 
Effect of Detergents on Antimicrobial Activity of Several Agents It is likely that [10]-gingerol acts as a sort of detergent. Thus, we examined whether other detergents potentiate antimicrobial activity of arbekacin on VRE.

The MICs of sodium dodecyl sulfate (SDS), Triton X-100 and Tween 60 against enterococcal cells were $256 \mu \mathrm{g} / \mathrm{ml}$, $>4000 \mu \mathrm{g} / \mathrm{ml}$, and $>160 \mu \mathrm{g} / \mathrm{ml}$, respectively, and their antimicrobial activities were low.

Sodium dodecyl sulfate (SDS) and Triton X-100 reduced the MIC of arbekacin by 4- to 128-fold, but Tween 60 did not affect the MIC (Table 5). Although Triton X-100 reduced the MIC of bacitracin and polymixin B in E. faecalis and E. faecium, it reduced the MIC of fosfomycin only in E. faecalis. Triton X-100 also reduced the MIC of ampicillin by 8- to 64fold, and that of norfloxacin by 8-fold in E. faecium (data not shown), which was not affected by [10]-gingerol.

\section{DISCUSSION}

We have been trying to find the compounds that potentiate the effectiveness of antimicrobial agents now clinically being used on drug resistant bacteria. Such compounds are expected to inhibit the resistance mechanism(s) in drug-resistant microorganisms. We have previously reported several effective compounds, such as epichatechin gallate, tellimagrandin I and coriladin, that markedly reduced the MICs of $\beta$-lactams in MRSA. ${ }^{12,14,15)}$ The mechanism of action of the

Table 4. Effect of Length of Alkyl Group of Gingerol on the Synergistic Activity with Arbekacin

\begin{tabular}{|c|c|c|c|}
\hline \multirow{3}{*}{$\operatorname{Agent}^{a)}$} & \multirow{3}{*}{ Compounds ${ }^{b)}$} & \multicolumn{2}{|c|}{ MIC for strains $(\mu \mathrm{g} / \mathrm{ml})$} \\
\hline & & \multicolumn{2}{|c|}{ E. faecalis } \\
\hline & & ATCC51299 & ATCC29212 \\
\hline \multirow[t]{4}{*}{$\mathrm{ABK}$} & - & 64 & 32 \\
\hline & [6]-Gingerol & $16 \quad(4)^{c)}$ & $16 \quad(2)$ \\
\hline & [8]-Gingerol & $64 \quad(1)$ & $1 \quad(32)$ \\
\hline & [10]-Gingerol & $2(32)$ & $2(16)$ \\
\hline
\end{tabular}

a) ABK, arbekacin. b) The concentrations added to the medium are, [6]-gingerol, $200 \mu \mathrm{g} / \mathrm{ml}$; [8]-gingerol, $25 \mu \mathrm{g} / \mathrm{ml}$ to ATCC51299 or $100 \mu \mathrm{g} / \mathrm{ml}$ to ATCC29212; [10]gingerol, $20 \mu \mathrm{g} / \mathrm{ml}$. These concentrations are lower than or equal to $1 / 8$ of their own MICs. c) Ratios [MIC of ABK]/[MIC of ABK with a compound] are shown in the parenthesis. latter two seemed to be the inactivation of penicillin binding proteins (PBPs), especially of PBP2' (PBP2a) that mainly conferred the $\beta$-lactam resistance to MRSA. ${ }^{16)}$ Recently we have found that baicalein showed synergy with tetracycline in MRSA. ${ }^{17)}$ This effect is partially due to the inhibition of the tetracycline efflux pump of MRSA by baicalein.

In this study we found that [10]-gingerol strongly potentiated the bactericidal activity of arbekacin in enterococci. This effect was not related to the aminoglycoside-modification enzymes that confer high-level aminoglycoside-resistance to enterococci. The intrinsic aminoglycoside resistance in enterococci is due to a low-level energy-dependent uptake of aminoglycosides. The cell membrane of enterococci is relatively impermeable to aminoglycosides because of the lack of energy formed across the membrane. ${ }^{2)}$ To facilitate the entry of aminoglycoside into cells, the combination therapy with $\beta$-lactams that inhibit cell wall synthesis is usually accepted for the treatment of infection caused by enterococci. The detergent-like structure of [10]-gingerol and our results obtained from experiments using several detergents suggested that [10]-gingerol caused some damage to the membrane of enterococcal cells and then facilitated the uptake of arbekacin into cells. [10]-Gingerol may act like $\beta$-lactams in the combination therapy of gentamicin and $\beta$-lactams.

Judging from studies in which structural analogs of [10]gingerol were used, the hydrophobic portion of the molecule seemed to be important to show the effect. Among the following three gingerols (i.e., [6]-gingerol, [8]-gingerol and [10]-gingerol), [10]-gingerol showed the strongest effect. These results suggest that the length of the alkyl group is important to potentiate the killing effect of arbekacin against enterococci.

[6]-Gingerol has been reported to have mutagenic activity. Also it has been reported that the active part might be the hydroxy group in the long alkyl group of the molecule. ${ }^{18)}$ There are few references concerning the toxicity of [10]-gingerol. More extensive studies using structural analogs of [10]-gingerol seem to be of interest.

Arbekacin is known to be stable against aminoglycosidemodification enzymes. Though the combination of gentamicin and ampicillin is commonly used to treat infections caused by enterococci, several studies suggest that the combination of arbekacin and ampicillin may become an alterna-

Table 5. Effect of Detergents on the MICs of Several Antimicrobial Agents in Enterococci

\begin{tabular}{|c|c|c|c|c|c|c|}
\hline \multirow{3}{*}{ Agent $^{a)}$} & \multirow{3}{*}{ Detergents ${ }^{b)}$} & \multirow{3}{*}{$\begin{array}{l}\text { Concentrations } \\
(\mu \mathrm{g} / \mathrm{ml})^{c)}\end{array}$} & \multicolumn{4}{|c|}{$\operatorname{MIC}(\mu \mathrm{g} / \mathrm{ml})$ of $\mathrm{ABK}$} \\
\hline & & & \multicolumn{2}{|c|}{ E. faecalis } & \multicolumn{2}{|c|}{ E. faecium } \\
\hline & & & ATCC51299 & ATCC29212 & 11506 & OU94 \\
\hline \multirow[t]{4}{*}{$\mathrm{ABK}$} & - & 0 & 128 & 64 & 16 & 16 \\
\hline & SDS & 32 & 4 & 4 & 2 & 4 \\
\hline & TX-100 & 250 & 1 & 1 & 2 & 1 \\
\hline & TW60 & 8 & 32 & 32 & 16 & 16 \\
\hline \multirow[t]{2}{*}{ FM } & - & 0 & 128 & 64 & 64 & 32 \\
\hline & TX-100 & 250 & 8 & 16 & 32 & 32 \\
\hline \multirow[t]{2}{*}{$\mathrm{BC}$} & - & 0 & 64 & 64 & 256 & 128 \\
\hline & TX-100 & 250 & 4 & 4 & 16 & 8 \\
\hline \multirow[t]{2}{*}{ PL-B } & - & 0 & $>1024$ & $>1024$ & 1024 & 512 \\
\hline & TX-100 & 250 & 32 & 16 & 32 & 16 \\
\hline
\end{tabular}

a) $\mathrm{ABK}$, arbekacin; FM, fosfomycin; BC, bacitracin; PL-B, polymyxin B. b) SDS, sodium dodecyl sulfate: TX-100, Triton X-100; TW60, Tween 60. c) Concentrations added in the medium are 1/4 MIC for SDS, lower than 1/8 MIC for TX-100 and Tween 60. 
tive therapy for infections caused by especially gentamicinresistant enterococci. ${ }^{9-11)}$ However the number of multidrug resistance enterococci, including high-level resistance to ampicillin is increasing in these days. E. faecium 11506 used in this study is a multidrug resistant strain, and is resistant to at least ampicillin, vancomycin, erythromycin, norfloxacin and aminoglycosides. [10]-Gingerol reduced the MIC of arbekacin in this strain as well as in other non-multidrug resistant strains. The combination of [10]-gingerol and arbekacin may be used for the treatment of infections caused by such multidrug resistant enterococci.

Acknowledgments We thank Dr. Manuel Varela of Eastern New Mexico University for critically reading the manuscript. This research was supported in part by a Grant-in-Aid for Scientific Research from the Ministry of Education, Culture, Sports, Science and Technology of Japan.

\section{REFERENCES}

1) Murray B. E., New Engl. J. Med., 342, 710-721 (2000).

2) Kare I., Konstabel C., Badstubner D., Werner G., Witte W., Int. J. Food Microbiol., 88, 269-290 (2003).

3) Moellering R. C., Jr., Weinberg A. N., J. Clin. Investig., 50, 25802584 (1971).

4) Huycke M. M., Sahm D. F., Gilmore M. S., Emerging Infect. Dis., 4,
239-249 (1998)

5) Sahm D. F., Marsilio M. K., Piazza G., Clin. Infect. Dis., 29, 259-263 (1999).

6) Tsai S. F., Zervos M. J., Clewell D. B., Donabedian S. M., Sahm D. F., Chow J. W., Antimicrob. Agents Chemother., 42, 1229-1232 (1998).

7) Boehr D. D., Lane W. S., Wright G. D., Chem. Biol., 8, 791-800 (2001).

8) Daigle D. M., McKay G. A., Wright G. D., J. Biol. Chem., 272, 24755-24758 (1997).

9) Kak V., Donabedian S. M., Zervos M. J., Kariyama R., Kumon H., Chow J. W., Antimicrob. Agents Chemother., 44, 2545-2546 (2000).

10) Kak V., You I., Zervos M. J., Kariyama R., Kumon H., Chow J. W., Diagn. Microbiol. Infect. Dis., 37, 297-299 (2000).

11) Kariyama R., Kumon H., Chow L., Zervos M. J., Takata T., Tabata M., Chow J. W., J. Antimicrob. Chemother, 42, 836-838 (1998).

12) Shiota S., Shimizu M., Mizushima T., Ito H., Hatano T., Yoshida T., Tsuchiya T., FEMS Microb. Lett., 185, 135-138 (2000).

13) Eliopoulos G. M., Moellering R. C., "Antibiotics in Laboratory Medicine," 3rd ed., ed. by Loorian V., Williams and Wilkins, Baltimore, MD, 1991.

14) Shiota S., Shimizu M., Mizushima T., Ito H., Hatano T., Yoshida T., Tsuchiya T., Biol. Pharm. Bull., 22, 1388-1390 (1999).

15) Shimizu M., Shiota S., Mizushima T., Ito H., Hatano T., Yoshida T., Tsuchiya T., Antimicrob. Agents Chemother, 45, 3198-3201 (2001).

16) Shiota S., Shimizu M., Sugiyama J., Morita Y., Mizushima T., Tsuchiya T., Microbiol. Immunol., 48, 67-73 (2004).

17) Fujita M., Shiota S., Kuroda T., Mizushima T., Hatano T., Yoshida T., Tsuchiya T., Microbiol. Immunol., 49, 391-396 (2005).

18) Nakamura H., Yamamoto T., Mutat. Res., 122, 87—94 (1983). 